\title{
Utopias da comunidade: o teatro invadindo o espaço urbano
}

\section{André Carreira'}

Submetido em: 09/04/2020

Aprovado em: 09/06/2020

DOI: $10.5965 / 2358092521232020185$

1 Doutor em Teatro pela Universidade de Buenos Aires, professor de Teatro na Universidade do Estado de Santa Catarina (UDESC). E-mail: carreira@udesc.br 


\section{RESUMO}

Este texto discute o conceito de comunidade efêmera relacionando-o à noção de teatro de invasão do espaço urbano. 0 artigo tem como premissa a prática teatral nas ruas como um exemplo de um projeto utópico que vê a formulação de comunidades efêmeras como objetivo de criação. A reflexão sobre a noção de utopia se vincula com a possibilidade de experiências plurais no espaço aberto das ruas. Uma cena em comunidade efêmera é vinculada a procedimentos teatrais que se sustentam na noção de presença.

Palavras-chave: comunidade efêmera, espaço urbano, teatro na rua.

\section{ABSTRACT}

This paper discusses the concept of ephemeral community in relation to the idea of a urban space invasion theatre. The text takes the theatrical practices on streets as examples of a utopian project that seeks to construct ephemeral communities on the cities. Utopia is related to the possibility of plural experiences in the street's open space. The scene as an ephemeral community is linked to theatrical procedures that are based on the notion of presence.

Keywords: ephemeral community, urban space, street theatre.

Este artigo apresenta uma reflexão sobre como as práticas de teatro na cidade, particularmente em sua modalidade de teatro de invasão, podem gerar experiências de comunidades efêmeras. Entendo que esta modalidade teatral se constrói como projeto utópico que busca nos comportamentos comunitários seu principal material. Esta utopia busca transformar momentaneamente os sentidos e os usos do espaço urbano através da conformação de comunidades efêmeras, cujo principal objetivo 
seria criar outras formas de relacionamento entre as pessoas que habitam a cidade.

Utopia aqui, não se refere à ideia de projetos impossíveis, mas sim a ações que buscam produzir transformações de determinadas realidades, e cujo acionar já implica intervir e modificar estas realidades, ainda que parcialmente. Utopia então seria uma força criativa que impele a realizar, ainda quando eventualmente seu objetivo final não seja alcançado plenamente.

Apesar de ter certeza que não é fácil estabelecer de forma simples o que seria exatamente a utopia que sustenta os mais diversos espetáculos teatrais que invadem a cidade, é possível identificar várias ideias que se relacionem com ela. Isto se refere a projetos utópicos que têm na proximidade e no compartilhamento de experiências, seu foco. Mesmo assim, é muito difícil estabelecer um acordo claro sobre como estas utopias funcionam no âmbito das artes da cena que dão forma, ou estimulam a construção de projetos artísticos. De todo modo, essa é uma ideia motriz para a reflexão sobre os vínculos entre estas formas espetaculares e elementos de um teatro comunitário. Não trato de oferecer aqui um modelo teórico, antes que isso proponho uma perspectiva para se discutir tanto os procedimentos criativos como nossos discursos políticos relacionados com um fazer artístico que se pretende comunitário.

Uma utopia implica a noção de ação e, especialmente, do desejo de ação que caracteriza a arte, principalmente a partir do século XX. A arte da atualidade, ainda que se sustente como um sistema produtor de bens culturais e de reflexões sobre a vida, também é, como diz o pesquisador espanhol Óscar Cornago, "um modo de fazer e de situar-se socialmente através desse modo de fazer, de se fazer a si mesmo e nos fazermos como coletividade." (2015, p. 17). Nossas ações utópicas funcionam nesta trama de modos de fazer.

Um aspecto importante destes projetos e suas utopias diz respeito à possibilidade da realização de uma experiência plural a partir de um ser-com os outros, ou para usar as palavras do filósofo Jean-Luc Nancy, o "ser plural" (2001). O elemento utópico estaria na busca de uma experiência teatral com a cidade, 
com as pessoas na cidade, com a comunidade de transeuntes, e isso implica enfrentar a discussão da possível-impossibilidade do comum (NANCY, 2001). A prática que daria forma a tal utopia pode ser definida como a busca de compor plurais. Neste sentido cabe observar que a pesquisadora Victoria Pérez Royo afirma que:

\footnotetext{
A expressão «compor o plural» implica duas forças contrapostas: uma centrípeta e outra centrífuga. A primeira denotada pelo verbo «compor» (colocar junto a, unir, reunir) e a segunda sugerida pela presença de «plural» (o distinto, o múltiplo, o divergente). Entre estas duas forças, de reunião e de dispersão, de cristalização e de dissolução, é onde se situa o nós: em uma situação móvel, cambiante, processual e dinâmica. (2016, p. 9)
}

Tomo esse ponto de partida para entender este acionar artístico organizado por uma busca que transcende o simples ato de representar personagens, ou de se exibir no espaço da rua. Parece-me fundamental estabelecer uma reflexão sobre as formas de manifestação artística cuja sustentação se apoia, principalmente, na transformação da condição das pessoas que circulam pelas ruas, isso é: de pedestres a ativas espectadoras. Cabe dizer que o adjetivo espectadora não supõe neste texto uma condição passiva de uma pessoa que "apenas" assiste a uma performance, mas compreende as diferentes formas de participação na cena a partir da situação de ser público.

Ao pensarmos sobre práticas teatrais comunitárias encontramos uma infinidade de formas e modos de operativos. Existem muitas possibilidades para reunir comunidades ao redor de uma experiência teatral, por isso não podemos definir uma prática teatral comunitária somente através de uma ideia de reunião em bairro, ou em um determinado contexto geográfico estável.

Como afirmou a pesquisadora Marcia Pompeo, esta é uma “modalidade teatral difícil de definir já que adquire diferentes formatos, ligados a diferentes instituições e finalidades" (2007, p. 77). Pompeo identificava "três modelos que se diferenciam 
em função dos objetivos e métodos serem decididos ou não pelas pessoas que participam dos projetos teatrais (a saber) 1. Teatro para comunidades 2. Teatro com Comunidades 3. Teatro por Comunidades" (2007, p. 78).

Partindo deste esquema busco pensar como as práticas do teatro que invadem o espaço urbano podem ser consideradas comunitárias. Tomo o modelo do "teatro com comunidades" para elaborar a hipótese do diálogo do teatro na rua com as comunidades efêmeras que se articulam no espaço da cidade. Isto é possível porque se pode identificar uma noção de comunidade efêmera que se manifesta em relação com os comportamentos das pessoas que habitam, de acordo com as mais diferentes modalidades, os espaços da cidade. O habitar neste caso não se refere somente às pessoas em condição de rua, mas a todas as pessoas que estão nas ruas em determinados momentos, independente dos motivos que às levam a circular na cidade.

Algumas abordagens do campo da antropologia também ajudam a delimitar as possibilidades de estudo sobre a relação da cena teatral com a comunidade. Como diz Pedro Costa em um artigo dedicado à observação etnográfica e as artes na cidade:

As novas práticas e lógicas heurísticas associadas à utilização de metodologias participativas (visuais ou outras) ou a assunção de uma investigação etnográfica mais virada para o estudo feito "com" as comunidades do que "sobre" ou "para" as comunidades têm dado passos significativos É [um] compromisso renovado com uma observação etnográfica intimamente comprometida com os territórios e as comunidades que são o alvo de pesquisa. (2018, p. 390)

Costa, ainda afirma que os artistas e as práticas artísticas podem ser objetos ativos da investigação que procura explorar contribuições da pesquisa etnográfica para o estudo das práticas artísticas em espaço urbano (2018). Este ponto de vista indica o potencial do fazer artístico como prática de conhecimento do espaço, um espaço que vivo porque se define pelos usos das pessoas que o habitam. Considero que isso pode ser diretamen- 
te relacionado com aquelas práticas que se fundamentam em um fazer com, um estar com, isto é, um teatro com a comunidade.

Tratar de definir o lugar da comunidade na hora de pensar a prática cênica como projeto volto ao pensamento de Pompeo que, dialogando com o pesquisador Baz Kershaw, considerava que o elemento fundamental para definir uma prática teatral seria a natureza do público e a comunidade de cada teatro específico. Além disso, Kershaw ressaltava que a estética deste teatro seria conformada pela cultura de comunidade do seu público. Isso permite reforçar a ideia que, identificando as tendências predominantes das culturas das ruas, poderíamos afirmar a existência destas comunidades efêmeras, e compreender como elas dialogariam com as formas teatrais que invadem as ruas (KERSHAW, 1992). Assim, podemos nos aproximar a uma perspectiva que reconheceria a conformação de práticas culturais - não apenas estéticas -, que permitem o estabelecimento de comunidades momentâneas.

O ponto de partida deste argumento é que os fluxos das pessoas nas ruas, eventualmente é interrompido pela articulação de um tipo de comportamento coletivo que permite a irrupção de uma comunidade transitória. Ainda que isso construa formas efêmeras de reunião, não deixa de ter uma potência comunitária que interfere na vida da cidade porque produz reunião e acionar coletivo.

Considerando isso, pode-se expandir a ideia de comunidade para ampliar nossa reflexão sobre as possibilidades técnicas, estéticas e sociais de um teatro que trabalha com essa efemeridade que caracteriza os processos das ruas. Além disso, pode-se discutir a perspectiva que analisa experiências comunitárias, com vistas a estudar práticas artistas que têm como objetivo principal compor plurais através da construção de objetos estéticos, particularmente com as formas das artes vivas.

O primeiro aspecto a se considerar neste caso é que compor plurais é trabalhar com o contraditório, como as tensões que se produzem quando ser reúne pessoas diferentes para construir dinâmicas convergentes como é o caso dos processos 
teatrais.

A ideia de compor plurais e de formar comunidades nasce do desejo de estar juntos, de estar com, o que seria para Jean-Luc Nancy o elemento fundamental para compreender o ser humano, cuja existência é um existir-com (NANCY, 2001). O mesmo Nancy afirma que este desejo comunitário sempre provêm de uma crise, ou seja, nasce a partir da percepção de que existe uma divisão e que portanto, seria necessário reunir novamente as pessoas (NANCY, 2001). Consequentemente, o que se pretende com o projeto comunitário seria superar a divisão colocando as pessoas em relação.

É interessante notar, como faz Rosaria Caldarone, que comunidade para Alain Badiou:

[...] é um impossível, mas é aquele impossível real que conduz o possível a uma transação com o impossível, que busca por tanto arrastar o possível para o impossível; mas, é preciso insistir nisso, arrastar em direção aquele impossível que o real já é; esta exigência provêm portanto de uma necessidade do real, de uma real necessidade, que se apresenta sempre fincada como uma farpa, aberta como uma ferida, farpa e ferida que significam uma ruptura, uma parada na circulação do sentido. (CALDARONE, 2013, p. 24)

Por princípio as comunidades não são perenes. Elas são resultado de acordos que têm uma duração determinada tanto por fatores internos como exógenos. Uma comunidade é um 'estar juntos', portanto, é uma prática coletiva, e se define pelas dinâmicas coletivas e individuais que criam tensões centrípetas que mantém a reunião ou a identidade das pessoas como algo comum.

A ideia de comunidade merece ser questionada para que se ponha em dúvida o componente idealista que supõe que em comunidade funcionaria sempre o encontro cuja tendência seria a harmonia, e a interação e comunicação plenas que seriam resultado do autoreconhecimento dos sujeitos.

Existe em nossos tempos, um sentimento de perda da comunidade tal como percebe Jean-Luc Nancy, quem se refere à 
uma ideia de comunidade inoperante, ou seja, uma comunidade que não demanda ou espera a realização de um projeto comum, nem o alcançar um objetivo ideal, mas sim supõe um intercâmbio criativo permanente (2001). Esta seria, segundo Nancy, uma comunidade com ausência de mito, uma comunidade que não se pode instituir, nem perpetuar, apenas esperar que se produza (2001).

Zygmund Bauman afirma que o modelo idílico de comunidade não funciona em nosso contexto cultural, pois o que temos como padrão comunitário são comportamentos fechados e protetivos que buscam mais defender-se das ameaças externas do que integrar (2003). Então a comunidade seria "um lugar cálido, um lugar confortável e aconchegante. [Mas] lá fora, na rua, toda sorte de perigo está à espreita; temos que estar alertas [...] estar de prontidão a cada minuto“ (BAUMAN, 2003, p. 7).

A ideia da comunidade rural que muitas vezes continua funcionando com um mito, ou melhor como uma ideia força que estimula a busca de formas relacionais mais humanas, parece haver sido banida pela lógica urbanista do desenvolvimento vertiginoso e do isolamento funcional.

Ao mesmo tempo, apareceu a partir de plataformas de internet, a ideia de comunidades virtuais, cujo desenvolvimento mostra principalmente a convivência e a informação circulando em verdadeiras bolhas de pensamento homogêneo. As "comunidades" de Facebook, Twiter, Instagran, são culturalmente aceitas como formas comunitárias e têm muito impacto na vida contemporânea. No entanto, as tendências à homogeneidade e à carência do encontro pessoal cara a cara, exige que duvidemos de seu real sentido comunitário. Haveria nestes ambientes um verdadeiro estar com? Deve-se observar neste caso a possibilidade do anonimato ativo na rede, ou da participação através de identidades falsas, o que diminuiria os compromissos inerentes do atuar em comunidade. No entanto, apesar de que estes ambientes virtuais são propriedades privadas de empresas multimilionárias, eles podem parecer ao que Baz Kershaw chamou de comunidades de interesse.

Em seus estudos Kershaw delimita duas noções de comuni- 
dade. Uma seria, como mencionado acima, a de comunidade de interesses, e a outra a de comunidade local. Esta segunda seria estabelecida pelas redes de relacionamentos articulados pelas relações pessoais dentro de uma área restrita. Já a comunidade de interesses que seria aquela constituída por associações definidas por um interesse comum claramente identificado. (HERSHAW, 1992).

No caso da comunidade de interesse, Kershaw diz que estas "tendem a ser explícitas ideologicamente, de forma a que mesmo que seus membros venham de áreas geográficas diferentes, eles podem de forma relativamente fácil, reconhecer sua identidade comum" (1992, p. 31). Esta identidade comum não estaria, necessariamente, dada pelo pertencimento a uma localidade específica, mas por um impulso momentâneo, ou um interesse que tenha força suficiente para gerar a percepção de que se está junto compartilhando um desejo, necessidade ou ponto de vista. Podemos pensar muitos exemplos deste tipo de comunidades, tais como sindicatos, gangues, igrejas, ou ainda comunidades cujos vínculos temporários são ainda mais frágeis.

A efemeridade não implica em que não exista vínculos comunitários. Isso dependerá de que as pessoas percebam ou não, que estão tomando parte em uma prática coletiva que Ihes permite criar algum tipo de identidade compartilhada e realizar as ações que se pretende concretizar, de tal modo a que ressoe a existência de uma comunidade.

Isto explica ações coletivas que emergem nas ruas de forma inesperada tanto em pequenos grupos de discussão como em reações mais contundentes. Este é um fenômeno fácil de ser observado durante as mobilizações de rua quando as pessoas começam a romper com o temor de tomar suas próprias decisões e eventualmente conformam pequenos grupos de ação em meio à multidão. Estas comunidades efêmeras podem ser percebidas durante a produção de saques ou outros atos coletivos violentos, bem como em iniciativas solidárias nos primeiros momentos, antes da intervenção institucional, durante tragédias como grandes acidentes, inundações e outros eventos que desorganizam a vida cotidiana. 
Este é um fenômeno que deveria interessar de forma particular às pessoas que desenvolvem experiências cênicas de invasão do espaço da rua, porque é um exemplo de como se pode pensar na formulação de comunidades momentâneas, ou melhor dito, comunidades efêmeras, como estratégia do teatro de invasão. Isto é especialmente importante se consideramos que a cidade se define como espaço fragmentado no qual o que importa é a intensidade de um determinado acontecimento em um lugar específico.

Esta cidade está construída pelas sobreposições do imaginário fabricado pelas instituições e do imaginário das pessoas que a habitam, por isso resulta concretamente do funcionamento dos seus fragmentos, e consequentemente das experiências de uso e fruição, mas especialmente como resultado das tensões do espaço urbano.

Em um artigo publicado na Revista Urdimento utilizo o ponto de vista de Simmel sobre o espaço urbano para afirmar que "a cidade que modula o sujeito que resiste culturalmente, e esta resistência conformaria, ao mesmo tempo, o modelo de cidade no qual se vive" (CARREIRA, 2009). O argumento que sustenta esta percepção parte do princípio de que a cidade é um organismo de contradições e atritos, por isso é um âmbito de disputas que instrumentalizam usos. Isso compõe o plural que definem os usos.

Naquele texto também fazia referência ao pensamento de Canclini e comentava que "as condições de impessoalidade que caracterizam as ruas funcionam de modo a garantir que ali, frente a alguns estímulos, os transeuntes possam exercitar esse desejo de autonomia ocupando novos papéis" (CARREIRA, 2009). Isto deve ser relacionado com a contradição com as forças institucionais, para as quais qualquer tentativa de autonomia põe em risco o ordenamento funcionalista da cidade. A consequência é que a tendência a romper, ainda que momentaneamente o funcional, abre fraturas e produz tensões, o que produz tanto respostas do sistema de controle como estimula experiências autônomas de ruptura, ainda que sejam somente no plano simbólico e imaginário. 
A ideia de compor plurais, que uso aqui como algo similar à noção de conformação de comunidades efêmeras, se apresenta como uma utopia em tempos de massificação e individualismo exacerbado. Vivemos um tempo hiperbólico das representações o que nos faz crer que a mercantilização de tudo seria algo infinito e insuperável. No entanto, é fundamental, como sugere Georges Didi-Huberman, não nos darmos por vencidas, e sabendo que a máquina do poder faz seu trabalho sem descanso, não ver apenas o todo, mas estar atentas "aos espaços intersticiais, intermitentes, nômades, improvavelmente situados das aberturas de possibilidades, dos resplendores, dos apesar de tudo" (2012, p. 31). Por isso, construir projetos utópicos de encontros plurais.

Penso a prática do teatro na cidade a partir dessa premissa, por isso proponho construí-la como uma produção de resplendores de resistência, de dissidência, de perfuração de brechas na continuidade de lógicas e fazeres alicerçados nos ciclos intermináveis do consumo, consequentemente como uma forma de estar junto com ainda que de forma efêmera.

A partir de Didi-Huberman que tem como referência o pensamento de Pier Paolo Passolini, podemos reivindicar para os e as artistas do teatro o papel de vagalumes que apesar da escuridão da noite, insistem com suas luzes intermitentes em oferecer a possibilidade de que algo seja visível. Enquanto uma enorme quantidade de insetos buscam desesperadamente o brilho que cega das luzes dos postes, em uma excitação muitas vezes mortal, os vagalumes realizam "sua dança vibrante precisamente no coração da escuridão" (2012, p. 41). Os vagalumes brilham para poder se reunir. Penso o teatro invadindo o espaço da cidade como uma estratégia de encontro mesmo que seja impulsada pela emissão dessa frágil centelha de luz que se pode oferecer através dos corpos em situação de jogo ficcional.

Parto destas imagens para afirmar o conceito de uma cena em comunidade efêmera, bem como para chamar a atenção para procedimentos teatrais que se relacionam com a noção de presença, da crise da representação, da dicotomia entre representar e apresentar, e de ética. Procedimentos que oferecem frágeis sinais de luz como estímulo à busca de um fazer estar 
com como utopia de proximidade.

Este é um caminho para a reflexão sobre as possibilidades de um teatro que invade a cidade e pensa sua atuação no aqui e agora, como modo de construção de uma experiência cênica que não se satisfaz com o plano temático das narrativas. Refiro-me a um teatro que busca a produção de experiências que comprometam as pessoas questionando os lugares estáveis nos quais todas nos colocamos, sejamos público das ruas ou artistas que invadem o espaço.

Pensar as práticas teatrais considerando-as também como práticas utópicas é colocar este fazer artístico em uma zona limítrofe que questionaria a natureza do teatro como prática cultural que responde principalmente à uma lógica comercial ou de prestígio. Uma ideia de um teatro sustentado por um projeto utópico pode soar romântica, mas isso pode ser considerado algo estratégico mesmo que seja a partir da imagem dos vagalumes mencionada anteriormente. Como dito anteriormente, utopia mesmo quando fracassa em alcançar seu objetivo máximo pode colocar em movimento a transformação, pois ir em busca de tal objetivo já é atuar sobre o plano concreto da vida.

Sei do risco que é partir de uma metáfora para a articulação de um pensamento que trata de questionar os sentidos do teatro na cidade, no entanto, parece-me potente esta imagem do resplandecer efêmero mas insistente, como exemplo do trabalho de quem faz teatro em um contexto adverso e hostil, como podem ser as ruas de nossas cidades. Além disso, reivindicar a efemeridade como tempo da experiência é também colocar-se em dissidência com a ordem funcionalista. Como afirma Roberto Da Matta:

Não é preciso especular muito para descobrir que temos espaços concebidos como eternos e transitórios, legais e mágicos, individualizados e coletivos. Tudo o que diz respeito ao poder político é, na nossa sociedade, conotado como duradouro ou eterno e marcado pelos monumentos e palácios. O poder como ordenador supremo de um mundo penetrado por todo tipo de conflito situa-se naqueles espaços de confluência do tempo e de 
Há nos vagalumes, argumenta Didi-Huberman, um sentido de comunidade que cria constelações cujo fim último é se reunir para o acasalamento. Estes insetos luminosos brilham avisando uns aos outros de sua existência quando a escuridão, em princípio, indicaria a impossibilidade do encontro (2012). Não vejo uma maneira mais interessante de pensar atores e atrizes dedicadas ao teatro na cidade, uma arte menor sistematicamente desprezada ou rechaçada pelos sistemas de poder.

Esta "escuridão" de tempos hiper preenchidos de produtos e de imagens que se sobrepõem em um ritmo vertiginoso não permite ver detalhes, somente o todo infinito. É ali que os vagalumes se fazem presentes chamando sutilmente a atenção para outras possibilidades. Há nisso uma ação que merece ser considerada como potente e provocativa para se refletir sobre a cena da rua. A comunidade efêmera dos e das vagalumes, uma possibilidade de estar junto compondo plurais que nos ofereçam momentos de deslocamento das rotinas do consumo eterno e infinito.

Considerando isso, a utopia que fundamenta os projetos de invasão das ruas está vinculada à criação de comunidades efêmeras estimuladas pelo interesse comum da participação em um momento lúdico. Portanto, é fundamental pensar um teatro que vai às ruas em busca de novas formas de relacionamento entre as pessoas baseadas no jogo e na experiência estética que desloca conhecimentos estabelecidos.

A estimulação de comportamentos lúdicos que possam se projetar para além do fruir intelectualmente um espetáculo, será fundamental para se produza algo que convoque a um jogo que desloque o lugar da observação de quem transita pela cidade. Assim, se poderá estimular uma participação que reorganize momentaneamente a ordem do espaço da cidade. A aposta está em que as pessoas possam decidir, com autonomia, mudando momentaneamente seus comportamentos, e desta forma construir comunidades nas quais operar coletivamente.

No caso da cultura brasileira o carnaval é a festa onipre- 
sente das ruas, e pode nos ajudar a visualizar como o e a cidadã se fazem foliãs criando duplos de si mesmas, e rompendo por curtos espaços de tempo as regras mais tradicionais da cultura.

A inversão da ordem que realiza o carnaval mostra o quão pequeno é o teatro na cidade quando este busca ser instrumento de ruptura de comportamentos. Seria impossível fazer algo semelhante ao carnaval dada sua dimensão cultural massiva. No entanto, muitos elementos desta festa podem servir como exemplo da potência do lúdico como vetor de transformação, e impulso para a produção de comunidades efêmeras. É a lógica da festa como motor comunitário o que interessa, pois a festa de rua impulsiona as pessoas a uma proximidade com outras pessoas desconhecidas a partir, principalmente do prazer de brincar. Como diz Biange Cabral:

Um dos prazeres do fazer teatral é que ele permite que o indivíduo se perca dentro, ou entre outros mundos, o que o leva a re-conceituar e re-experimentar as relações entre ele e os outros - outras pessoas, outras histórias, outras realidades, outras linguagens. É esta possibilidade de estar perdido que torna possível que ele encontre significados além do banal, que ele possa ler a cena e o mundo através de outras perspectivas. (2009, s/p)

Uma tarefa iniludível para o teatro de invasão é descobrir em que condições e dimensões a cena da rua poderia gerar momentos nos quais os e as transeuntes poderiam decidir fazer parte de uma comunidade efêmera a partir do jogo da ficção.

Aqui cabe dizer que experiências de teatro comunitário como o grupo argentino Catalinas Sur, ou do Grupo Faces de Primavera do Leste (MT), ou ainda de diferentes práticas relacionadas com o modelo do teatro em trânsito, têm como comum o fato de que as pessoas que participam têm prazer em estar em cena, ou estão convencidas da importância da tarefa. Algumas experiências do Erro Grupo de Florianópolis, também estão baseadas na hipótese do desejo das pessoas jogarem ocupando papéis dentro da performance cênica. Montagens na cidade do grupo cearense Teatro de Caretas, do goiano Teatro que Roda, 
ou da paulista Cia. São Jorge de Variedades também apontam para a incorporação do público como fator central dentro do jogo ficcional, como elemento estruturante do espetáculo que gera uma prática comunitária efêmera. Estas, entre uma infinidade de propostas cênicas nacionais e estrangeiras, experimentam com formas espetaculares nas quais pode-se observar que o jogo funciona como inversão do mundo (DUVIGNAUD, 1982) e transformação do tempo do estar juntos no espaço público.

O ambiente urbano deve ser compreendido como algo que não se refere apenas aos aspectos espaciais e arquitetônicos da cidade, deve-se considerar o fluir dos corpos e a experiência corporal de cada indivíduo neste espaço como componente que constrói o ambiente.

Na cidade as pessoas convivem criando redes momentâneas de relações. Estes acordos de convívio variam dependendo do momento, lugar e tipos de pessoas que nos circundam. Assim, é muito distinta nossa disposição para o convívio quando estamos dentro de um vagão do metrô ou quando nos sentamos em um banco de praça. Nestas conformações diversas do espaço urbano nossa percepção da cidade e dos acontecimentos se dá de modo distinto de forma que possamos tecer nossas estratégias relacionais. Entre elas também estão nossas formas de sentir segurança.

Por isso, quando se pensa em uma ação teatral que busca formular comunidades através da fugacidade do espetáculo teatral, estamos dialogando com esta complexidade de fatores. A comunidade efêmera está conformada por cidadãos e cidadãs em processo de utilização da cidade, isso implica pensar o funcionamento do acontecimento teatral considerando uma lógica espacial que se define a partir das regras explícitas ou invisíveis que interferem no habitar este espaço.

O principal elemento do funcionamento da cidade que será posto em crise com o teatro de invasão é o fluxo ( $\mathrm{LYNCH}, 2006)$. Certamente, isso se dará em um fragmento pontual da cidade, mas mesmo assim tal coisa pode implicar na modificação do tempo de circulação o que implica no passo inicial para articular uma experiência comunitária momentânea. Deixamos de ir 
e vir e por um lapso de tempo, e podemos começar a reconhecer outras pessoas que fazem a mesma coisa atraídas por uma performance cênica. Assim começam as micro-rupturas que propiciam novas conformações no espaço e novas possibilidades de vínculos. O reconhecimento mútuo da polarização pelo espetáculo forja a comunidade efêmera na qual as pessoas participantes colaboram entre si facilitando a construção do espetáculo. Estas pessoas se dispuseram a ser espectadoras da cena e assim reconhecem atores e atrizes como copartícipes deste momento comum.

O elemento do prazer não pode ser considerado um algo secundário, isso deve ser pensado como uma força fundamental da articulação coletiva. Diferentemente de outras iniciativas comunitárias nas quais o sentido da tarefa, seu impacto na vida prática, ou seja, seu caráter funcional pode ser quase que exclusivamente o fator que reúne as pessoas, no teatro o prazer de fazer a cena, e vê-la realizada frente a uma audiência aparece como prioritário. O jogar a cena, o estar em jogo é um componente aglutinador chave e determinante para que exista o teatro como acontecimento.

Qualquer pessoa sabe que o teatro não interfere diretamente na resolução dos problemas práticos. Ele é uma fala que pode produzir experiências, afetividades e pensamentos que, posteriormente, podem estimular as pessoas em relação a algo concreto. Antes de ser um instrumento da racionalidade instrumental, tal como supõe o modelo de Augusto Boal, o teatro é uma experiência corporal, é acontecimento no qual se produz afeto, isto é, ele é uma experiência transformadora em si mesmo. Por isso, tanto o prazer do fazer como do assistir é uma componente chave que também está relacionado com a ideia de comunidade, dado que o fazer/assistir se dá sob a forma de uma comunidade efêmera de interesses.

Nenhuma apresentação teatral pode funcionar - sob as mais diferentes formas e modelos - se não se produz uma dinâmica comunitária cujo fim é fazer que o jogo da ficção funcione. Usualmente, a pessoas do teatro usam um termo da semiótica para definir isso como "pacto ficcional", mas também pode- 
mos falar de um acordo de comunidade efêmera, que é o que aproxima e reúne elenco e audiência, baseado não apenas na manutenção da lógica ficcional, mas também da cumplicidade relacionada como o prazer de fazer/ver. Neste tipo de teatro há um mútuo reconhecimento que alimenta o prazer da cena como encontro.

Outra questão que merece atenção quando pensamos nas potencialidades comunitárias do teatro na cidade diz respeito aos aspectos estéticos desta cena, e a importância disso no fenômeno social. Este é um tema muitas vezes relegado a um segundo plano, ou até mesmo menosprezado em privilégio da função social e política da ação comunitária, o que via-de-regra reforça os aspectos temáticos do texto dramático levado à cena.

Marcia Pompeo diz que a reflexão estética não é um "foco explícito de muitos trabalhos de Teatro na Comunidade, [no entanto] a questão estética também está presente." Esta pesquisadora ainda remarca que "a produção de teatro, nesta área, é talhada pela cultura da comunidade" e afirma que "trata-se de uma estética com padrões particulares que não pode ser julgada segundo parâmetros estranhos a ela". (2007, p.79).

O elemento estético deve ser considerado como um fator chave do acontecimento teatral no espaço da cidade, porque esta é a camada que produz rupturas que mobilizam as pessoas que andam pela rua ao confrontar a cotidianidade com a dobra ficcional. Não se pode falar de jogo se não saímos dos fluxos cotidianos, e para isso a dimensão estética é fundamental dado que é exatamente o que pode introduzir um elemento novo nos tempos das ruas.

Entenda-se que ao reivindicar a importância da experiência estética não estou falando de um determinado nível de qualidade estética canônica da encenação, ou da técnica de atuação. Refiro-me a uma produção de trabalho que explore as possibilidades dos códigos teatrais contribuindo para que o público seja convidado a viver um processo de gozo estético e de aprendizagem de linguagem. Isso é um componente básico de toda produção artística que pretende oferecer às pessoas algum crescimento intelectual sensível: estimular o contato com propostas 
estéticas que não respondem de forma imediata aos padrões já reconhecidos.

Impossível pensar uma transformação através da arte que considere apenas o nível temático da experiência. O confronto com diferentes estéticas também é uma forma de estimular a audiência a realizar experiências que propiciem crescimento pessoal, e favorecer o gozo da incorporação de outros padrões artísticos. Biange Cabral faz referência ao ponto de vista da abordagem antropológica do ritual realizada por Victor Turner (1988) para afirmar o potencial das:

[...] associações com uma forma teatral em processo como atualização cultural dos participantes. [pois] Em vez da ênfase na comunicação de aspectos culturais, Turner vê o ritual como uma possibilidade de lidar com o poder, quando não há outra maneira de fazê-lo. (CABRAL, 2009, s/p)

Assim, podemos pensar na força de formas que convocam a uma participação que ritualiza o próprio fazer da cena, mais do que convidam a se assistir como público relativamente passivo a um espetáculo que conta uma história (CABRAL, 2009, s/p). Por isso, é fundamental que as práticas teatrais que invadem a cidade se preocupem em oferecer às comunidades efêmeras que se articulam nas ruas, o desafio de lidar com propostas estéticas que não repousam em modelos completamente conhecidos e digeridos do discurso teatral. É preciso acreditar no potencial criativo do público, e supor que estes desafios serão aceitos e multiplicados pelas mais diferentes pessoas que transitam pelas ruas.

Isso deve ser relacionado com o desejo de fazer teatro na cidade para criar condições para o estabelecimento de novos vínculos entre as pessoas que habitam a cidade. A experimentação estética também diz respeito ao desejo de se propor acontecimentos teatrais que intensifiquem experiências comunitárias efêmeras como um elemento vital de interferência no ambiente urbano.

Reafirmar a instalação de comunidades efêmeras neste 
ambiente, é tratar de deformar os projetos hegemônicos institucionais, e também de criar rupturas com as tendências culturais que se instrumentalizam facilmente os comportamentos regidos pelo ordenamento funcional das ruas. 


\section{REFERÊNCIAS}

BADIOU, Alain, Filosofia e politica, en Agamben, Badiou, de Carolis, Nancy, Russo, Zanardi: comunità e política. Napoli: Ed. Cronopio, 1993.

BAUMAN, Zygmunt. Comunidade: a busca por segurança no mundo atual. Rio de Janeiro: Zahar, 2003.

CABRAL, Biange. Impacto e risco na escola/comunidade. In: Memória. ABRACE V, Salvador, UFBA, 2001.

O Teatro no espaço da cidade: o lugar praticado. O Percevejo, Sevilla-Espanha, v. 1, n. 1, s/p., 2009.

CALDARONE, Rosaria. La comunidad de los otros. A partir de Jean-Luc Nancy. Thémata. Revista de Filosofía. n. 47, p. 24, 2013.

CARREIRA, André. Teatro de rua como ocupação da cidade: criando comunidades transitórias. Urdimento, Setembro. n. 13, 2009.

CORNAGO, Óscar. Ensayos de teoria escénica: sobre teatralidade, público y democracia. Madrid, Abada Editores: 2015.

COSTA, Pedro. Práticas artísticas e espaço urbano: renovando compromissos com a observação etnográfica. Etnográfica Revista do Centro em Rede de Investigação em Antropologia, Portugal, vol. 22, n. 2, p. 390, 2018.

DA MATTA, Roberto. A casa \& a rua espaço, cidadania, mulher e morte no Brasil. Rio de Janeiro: Editora Rocco, 1997.

DIDI-UBERMAN, Georges. Supervivencias de las luciérnagas. Abada Editores: Madrid, 2012.

DUVIGNAUD, Jean. El juego del juego. México: Fondo de Cultura Económica, 1982. 
GARCÍA CANCLINI, Nestor. Imaginarios Urbanos. Buenos Aires: Eudeba, 2005.

HARVEY, David. Ciudades rebeldes: del derecho a la ciudad a la revolución urbana. Madrid: AKAL, 2013.

KERSHAW, Baz The Politics of Performance: Radical Theatre as Social Intervention. Londes: Routledge, 1992.

LYNCH, Kevin. A imagem da cidade. São Paulo: Martins Fontes, 2006.

NANCY, Jean-Luc, La comunidad desobrada. Arena Libros, Madrid, 2001.

PÉREZ ROYO, Victoria. Componer el plural. Una introducción. Componer el plural Escena, cuerpo, política. Barcelona: Mercat de les Flors / Institut del Teatre / Ediciones Polígrafa, 2016.

POMPEO, Marcia. Tentando definir o teatro na comunidade. DAPesquisa, Florianópolis, v. 2, n. 4, p. 77-79, 2007.

SIMMEL, Georg. As grandes cidades e a vida do espírito. Mana, vol. 11 n. 2. Rio de Janeiro, p. 25, out. 2005.

TURNER, Victor. From Ritual to Theatre. The human seriousness of play. New York, PAJ Publications, 1988. 